\title{
The Changes of Mother Parenting in China and Its Current Status
}

\author{
Meichen Zhang \\ Psychology, Western Washington University, Bellingham WA 98225, the United States \\ Corresponding author's Email: meichen_zhang@yahoo.com
}

\begin{abstract}
The article analysis the important changes in the role of mother from ancient China and modern China and explore the inner characteristics of mother under different historical background. Mother's responsibility changed from sampling fostering the kids to planning and scheduling kids' life and education. With the development, under the background of market-economy globalization and education globalization, the words such as "pushing the kids", "education involution", "education depending on mother" emerged, the public is stricter on mother's responsibility and function. In modern society, with the decrease in children among a family, parents focus more on the elite education of their kids. The division of labor among males and females reflects the characteristic of mother in kids' education, thus mother's value is bonded with their kids. Under the market economy development in the education sector, and with the over publicize of social media, education became even more competitive. Due to the reason of China's traditional culture and the society's impression about females, the development of mother itself as an individual is difficult. However, with social progress, the transition of the catachrestic of mother show the progress of women, we can feel that woman's right and discourse power is gradually increased. The increase of women's self-worth can not only reflect on the responsibility of parenting but also can lead women to the position of decision-makers and gain the right to plan education activities as well as their life activities of their children. To a certain extent, this promoted gender equality.
\end{abstract}

Keywords: Mother, Nurture, Education, Gender Equality

\section{INTRODUCTION}

Against the background of today, the connotation of "mother" in China has changed. It reflects the progress of The Times and the transformation of thoughts. From another point of view, different times have injected new contents into its functions. Traditional Chinese society is a social system dominated by patriarchy. Men dominate all hierarchical regulations and social order, and women are just subordinates of men and "aphasia" under patriarchy. As the most crucial role of women -"mother" can clearly show the core of patriarchy. With the change of times, mothers began to re-enter society as independent individuals, and women were no longer just "appendages" of men. In addition, the awakening and development of feminist thought, the improvement of women's economic status, the popularization and development of education, and many other factors have given women more rights to speak and make decisions, whether in the family or society. By sorting out the historical evolution and essential connotation of motherhood, we can see the development of feminism in Chinese history and contemporary times.

\section{THE DEVELOPMENT OF THE ROLE OF BEING A MOTHER}

From ancient to the present, mother played an important role in family life. With the development of the times, people are changing their thoughts on the definition of a mother's responsibility. In ancient China, under the feudal society, the traditional culture of agricultural society affects the economy and then develops into the typical division in labor among families. The husband is in charge of earning money to support the family, while the wife is responsible for doing housework, thus women's family status is more focused on producing offspring. Furthermore, in ancient society, people embraced the belief of mother's honor increases as her son's position rise, only those who can give birth to children can receive reorganization of the community and the family. For children's education, mother is required to get a lead and make themselves as 
examples, and their moralities are required strictly by the public. Although mother undertake most responsibility of rearing and educating, their family status is still mighty. Under the common sense of man is superior to woman, mother is hard to gain their social status as individual people, and their values are affiliated with manpower.

Along with time change, with the rapid economic development, feminine consciousness awoke and people start to search for equality between males and females. With the idea of education widespread, the position of women was enhanced. At that time, China launched series of policies encourage women to step outside of the family and step into the workplace. In the 1950s, under the environment of encouraging women to work, women can walk out to attend social labor by their own will. This movement not only raises the ratio of women attending work, but also supports the legality of women attending social activities, and establish a solid base of female getting political status. The children are not seen as family property, but the "flower of the country" .[1] The responsibility of children's education is not undertaking only by mother, the government takes a great portion of the responsibility and follows establish the functional system of kindergarten. The launching of the birth control policy limited the number of children, and sub-replacement fertility occurs. The human resource competitive system changed the way of parenting and shaped the phenomenon of paying equal attention to both caring and educating. Moreover, according to Tao, the change of mother's ideology lead mother's characteristics switched from caring for the kids to educate the kids.[2]

Comparing to ancient times, mother in modern eras has higher family status. After the founding of the People's Republic of China, the Chinese government introduced the policy of Marriage Law, which legally protects female family status and social rights. Comparing to the past, rearing children is not only dependent on mother, father getting more involved in the daily activities and rearing the children together. Mother have relatively more economic power and the right to make decisions that get rid of the past affiliation norms. However, the traditional ideas are deep-rooted in citizens, which burden the responsibility of rearing children mostly on mother, the conflicts of work and life occur on mother.

\section{THE CURRENT STATUS OF MOTHER}

With the awaken and the implementation of women's rights, the catachrestic of women changed from fulfilling families' needs and social requirements to pursuing individual life and development. However, mother is always the main character in rearing children and educating children. With the elevation of female education and their social identities, mother has more abilities on children educating. By systematically studying, internet communicating, individual experience aggregating, as well as scientific learning mordant ideas, the characteristics of mother's identity increased.

Among daily life, mother is always playing the role of guardian, by introducing scientific parenting children, mother delicately making plans of children development schedules, at the same time, they grasped the right of making decisions. The appearance of the words "intensive mothering" required mother to be more devoted in children's daily life, it indicates that mother should keep the children as the center and their responsibilities are irreplaceable. This rigidly requires a mother's self- accomplishment such as the efficiency of communicating with their children and the effectiveness of the schedule which balancing children's life and study. Among different arrangements of casual activities, mother and children are under an equal status. Mother usually is responsible for family planning and the life planning of their children, however, the father is relatively responsible more for supporting the family financially. The same idea shares by Xiao, who indicated that traditionally speaking, mother takes care of the family, while in the modern era, grandparents take this responsibility.[3]

Mother became more agent-like in children's education. The competition of education became more severe and made mother responsible for more. Mother will schedule individualized paths for educating their children and finally settled to the specific courses in the education and training market.[4] Compared with the father, mother is responsible more for monitoring and implementing the schedule. A family which highly focuses on children's education requires them to devote more not only financially, but also emotionally. Economic capital, social resources, cultural capital, and human involvement are all needed. Mother nowadays is gradually substituting teacher's role to programming their children's future. Also, many mothers are highly focused on school activities, they established good relationships with teachers to draw teacher's attention more to their children. Furthermore, many mothers are keen on scheduling extra tutoring courses to enhance children's abilities. They develop resources of their own and combined them with internet information to know more about the education market and school requirements. By doing so, they help their children take a more advanced status in education competitions.

\section{THE REASON FOR THE FORMATION OF MOTHER}

The occur of low fertility is because China strictly implemented the policy of birth control, it relieves the pressure of population but at the same time, it shirked the size of the family. Also, people's thoughts about marriage changed, the traditional marrying ideas get 
lashed out and result in a significant increase in the ratio of unmarried and late marriage. With the lifting of women status and women' rights, more and more female is liberated form family, they embrace the society and start they own career. The increase in the cost of rearing babies also affects the plan of giving birth. With the children's aging and the increase of educational expenses, the burden of a family gets heavier and heavier. Cannot afford became a popular reason for normal families decides not to have a second child. This leads to the pheromone of only one child in the family, and the family will more focus on his or her education. Due to the traditional thoughts of bloodline and the thoughts of reciprocal and filial piety, the idea of bringing up children for being looked after in old age still exists. Lots of families see children as a future investment, they devote lots of resources to the children and expect them to stand out among others.

The over-publicity of media and advertisements is the outcome of education marketization and the development of the economy. The idea of "knowledge is wealth" is deeply planted in people's minds, and these advertisements make the competition of human resources even more stressful. Different types of tutoring courses and learning advertisements proclaim some extreme views. These views broadcast many times by social media and affects people' thought as well as exaggerates their stress towards their child competing with other children. The idea of globally competitive education and neoliberalism catalysis the idea of education is more a reflection of parents' will and wealth than students themselves. These ideas enhance the investment of parents in their children for making sure that their children will not be left behind in the beginning.

According to the current division of labor inside a family, in most cases, males are still in charge of earning money to support the family, while females are responsible more for doing housework. Among raising children, the role of the father devotes more money, while the role of mother devotes more time. Under the stereotype, caring for children is more a women's gift, this leads to the ignorance of other abilities that women get. Due to the significant difference in the division of labor inside a family, mother's value is more attached to their children, while the father's value is unlikely to show by their children, thus the father's devotion of time is significantly less than mother's. Male's success can be reflected in their workplace, among current mechanism of job, man- orientated jobs are much more than women's, female is still hard to get social ratification and proper appraise .[5] This shows that in our current society, women have fewer opportunities than the man to get promotions in their careers. At the same time, the requirement for females still stagnates in their ability to balance work and life. For example, inside a family, housework is mostly assigned to women, and men have fewer such requirements.

\section{CRITICAL THINKING AND OUTLOOK}

We cannot deny that even under current society, there is some region have thought of man is prior then women. Thousands of years of feudalism have had a far-reaching effect on many families, it is the main obstacle to the promotion of women's rights. Simultaneously, long-term suppression by men left a weakness in women such as inferiority, these characteristics also slow the progress of equality. The stereotype of women makes them difficult to express their advantages outside the family. In the workplace, women lost development opportunities, and lose their true value during caring and laboring .[5] Compared with women, men in the workplace still obtain the directing power, they have more opportunities to get promotions. While women are trying their best in balancing work and life, most men slight on their work. This results in the fact that most financial income is earned by men, and thus enhances the dependency of wife to husband. When there are conflicts inside a family, usually women are the side who compromised. The responsibility of raising the children and doing the housework is mostly on women can reflect apparent gender discrimination .[6]

With the development of the women's rights movement and the advertisement of equality, women's social status has significantly increased. Women nowadays have more rights to make decisions, not only in daily life but also among children's future planning. Mothers can rationally plan their children's future can advance their self-value. When women have more options to express themselves, such as attending parents' fair host by the school, they can gain more opportunities to show their abilities to help the teacher in managing children. In social life, females have more opportunities to have a voice and express themselves. "Being yourself" has become one of the defining symbols of our time, changing stereotypes about females. In the process of individuation, women are more "living for themselves" than just relying on family or husband's accessories. At the workplace, with the launch of Labor law, some terms protect women's rights legally, this help even more female free from housework and start their career to support the family. Women became more energetic in expressing themselves, to a great extent, this policy help increase the social status of women. Family expenses are not supported by men, women get more decisions right as they gain more money. This result in male no longer gets the full power, and many issues can be solved by discussion. Mothers are no longer simply responsible for raising the children, they can be decision-makers in children's lives, all these reflect the equality of females and males. 


\section{CONCLUSION}

According to the study, with the continuous awakening of female consciousness. The functions of mothers have been improved in taking care of the family and raising the kid. The mother tends to pay more attention to personal interests, capital investment, and long-term development, which is qualitatively different from the role of mothers in traditional Chinese society. However, it can be seen, many factors in hindering the further growth of feminism and her mother's function. For example, exaggerated in the media, made excessive competitive education, made every family, especially each mother, involved in competition in the children's education. As a result, mothers put more into time and energy, interest, and investment in their own time. In this sense, mothers are forced to become "victims" of domestic care labor. In a sense, the change of mother image is the development of women's awareness of self-help rights and interests and the requirements of traditional patriarchal culture and consumer culture. This puts forward higher requirements for women's quality, and people have more expectations and requirements for mothers in the new era. Therefore, it puts more stress on the mother. How can we balance motherhood and the values of female independence and not just the women themselves but the society as a whole? In addition, we also see the impregnation of the traditional culture of more than two thousand years and the existence of the "son preference" concept. It makes some parts of the development of feminism and the mother function display still severely hampered by cultural factors, against the mother science and health raising children, more conducive to the improvement of family relations, will lead to mothers becoming serious in their family dependents.

By understanding the historical evolution and contemporary development of maternal care for children. We can see the changes in maternal care in traditional Chinese and modern societies over the past two thousand years and further understand and reflect on the emergence and development of the Patriarchal system and feminist thoughts in China.

We observe that females with the awakening of individual consciousness and the education level of the ascension of males. As a result, women's relations in China have a more significant change. Women are no longer in traditional society fully the role of the oppressed. With the development of feminist thought, the mother has a substantial boost in the position in the family, has more and more voice and family affairs. On the one hand, the evolution trend of Chinese mothers' child-rearing reflects the changes of roles under the background of The Times. On the other hand, it also reflects the changes in the functions of male and female relations in family and social affairs. If we understand the differences in mothers' child-rearing roles, we will better understand Chinese social concepts.

\section{REFERENCES}

[1] Jin Yihong. Chinese Working Mothers in social Transformation [J]. Xuehai,2013,\{4\}(02):56-63.

[2] Tao Yan-Lan. Shaping The Ideal Mother: The Construction of Parenting Knowledge in a Changing Society [J]. Journal of Women's Studies, 2016, \{4\}(05):25-37.

[3] Xiao S W. "Yan Mother Ci Zu" : intergenerational cooperation and power relations in child rearing [J]. Sociological research,2014,29(06):148-171+244-245.

[4] Yang Ke. The Broker of Motherhood: The Change of Motherhood in the Context of Educational Marketization [J]. Journal of Women's Studies, 2018,\{4\}(02):79-90.

[5] Xiao Suowei, Jian Yilun. Nursing labor and Social Inequality: Feminist Studies and its Implications [J]. Journal of Women's Studies, 2020, $\{4\}(05): 12-27$.

[6] Tong Xin. Nursing Labor and Gendering Labor Polity $[\mathrm{J}]$. Jiangsu Social Sciences, 2017,\{4\}(03):43-54. 